\title{
Engineering Approaches in Life Science and Health Care
}

\author{
Christine C Huttin* \\ University Aix Marseille, France \\ *Corresponding author: Christine C Huttin, University Aix Marseille, France. \\ To Cite This Article: Christine C Huttin. Engineering Approaches in Life Science and Health Care. Am J Biomed Sci \& Res. 2018 - 4(5). AJBSR. \\ MS.ID.000838. DOI: 10.34297/AJBSR.2019.04.000838
}

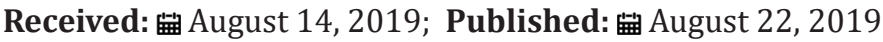

\begin{abstract}
Revision for Abstract 2019
Contrary to engineering sciences, where the cost criterion is an issue for engineering in optimization of physical systems; in medical and health systems, usually highly regulated for market access and reimbursement of medical services, researchers are used to combine two criteria, cost and effectiveness or cost and efficacy. The field is usually called outcome research, and it relies nearly exclusively on a specific industry called outcome research firms, mainly recruiting consultants from the life science industry firms or researchers trained in economic evaluation techniques (especially pharmacoeconomics).
\end{abstract}

In the US however, important political circles have rejected these double criteria especially in the Senate to keep technological trajectories and research and innovation investments close to the production efficiency curve (Philipson et al. es, $\mathrm{xx}$ ) in order, not to be too disruptive. The field is Comparative Effectiveness Research (CER), versus what is called in most European regulated markets HTA, where usually both cost and effectiveness criteria are used. This on-going problem of course is debated to keep a good adjustment of supply and demand needs, and the more regulated the health system, the more, normally, local demand needs, and its variations are integrated. However, the current globalization stage of both supplies, but also demand with the implementation of Universal Health Coverage, lead to reconsider this debate since local adjustments of supply and demand, even regional adjustments are not enough. Conventional outcome research is therefore challenged and new methodological approaches are explored, among them, MCDAs and especially relevant to engage multistakeholders in a consensual process over the adjustments of supply and demands.

However, researchers on patterns of utilization of medical care (especially pharmaco epidemiologists) removed, especially after September 11 events, economics or cost criteria from the studies, with a top priority setting for research on safety issues. This leads to reduce the access to market to a lot of potential useful medicines and may have contributed to a disequilibrium between the portfolio of medicines of major firms and the markets where they could get enough returns. Too marginal return of investments in their drug incremental innovation especially was jeopardized by this process. In the current situation, major R\&D areas have been withdrawn from the research pipelines, the most critical being the AMR areas.

Discussion at Padova and Paris with Prof Fraga lead to review engineering approaches used not only for the supply of drugs (such as the optimization of penicillin production presented in Paris) but also engineering approaches to re design workflows of tasks in physicians' practices, to possibly compare ways to adjust supply and demand, with scenarios analysis. A previous research project on transaction cost economics in primary care (as a collaboration with the California Medical Association) lead to identify areas of uncertainty where such approach could be useful: impact of pandemics, failure of computer system, loss of liability insurance. The paper will propose some optimization solutions for efficiency of the workflow in situations of uncertainties, in primary care. For instance, physicians will know in advance, seasons and announcements for a flu epidemic, but not exactly the day or the week it might hit their populations of patients, especially more or less anticipated events such as flus, allergies, others, on a weekly basis. The current discussion paper will formalize some scenarios within the engineering approach on transaction costs approach and Huttin C application for primary care.

Keywords: Engineering approaches; Analytics healthcare; Algorithms for medical markets

\section{Introduction}

Contrary to engineering sciences, where the cost criterion is an issue for engineering in optimization of physical systems, in medical and health systems, regulated for market access and reimbursement of medical services, researchers are used to combine two criteria, cost and effectiveness or cost and efficacy. The field is usually called outcome research; it nearly relies exclusively on a specific industry called outcome research firms, mainly recruiting consultants from the life science industry or researchers trained in economic evaluation techniques (especially pharmacoeconomics).

However, in the USA, some political circles have rejected these double criteria, for instance in the Senate, to keep technological trajectories and research and innovation investments close to the 
production efficiency curve in order, to be less disruptive. The field of Comparative Effectiveness Research (CER) is a good example, since stakeholders, mainly among payers, prefer to compare treatments on clinical utility rather that judging products and technologies based on cost effectiveness ratios [1,2]. On the contrary, in highly regulated markets such as European markets, "Health Technology Assessment" (HTA), usually both cost and effectiveness criteria are used, especially to calculate Qaly thresholds per country or groups of countries [3,4]. These differences in priority setting among dominant criteria are regularly debated to keep a good adjustment of supply and demand needs and help arbitrations between innovation and reduction of prices and costs $[5,6]$. Usually, the more regulated the health system, the more local demand drives the decisions to secure larger market access for affordable treatments, while more liberal systems are more supply driven with medical technologies. However, the current globalization stage of both supplies, but also demand with the implementation of Universal Health Coverage, lead to reconsider this debate, since local adjustments of supply and demand, even regional adjustments are not enough. Conventional outcome research is therefore challenged, and new methodological approaches are explored; especially to engage multistakeholders in a consensual process over the adjustments of supply and demands, with different perspectives, to integrate the political economies of various groups of developed and less developed countries [7] and to select appropriate methodologies [8] (e.g. use of Multi Criteria Decision Analysis, Discrete Choice modeling and other preference research methods to adjust by sub groups of populations, calculations of Incremental Cost Effectiveness Ratios (ICERs) thresholds according to degree of novelty of treatments or per indication, etc.).

However, researchers on patterns of utilization of medical care (especially from pharmaco-epidemiologists) removed, especially after September 11 events, economic and cost criteria from the main epidemiological studies, with a top priority setting for research on safety issues. This lead to reduce the access to market to potential useful medicines and may have contributed to a disequilibrium between the portfolio of medicines of major firms and the markets where they could get enough returns. Marginal returns of investments in the company's drug incremental innovation especially was jeopardized by this process. In the current situation, some major R\&D areas have been withdrawn from the research pipelines, the most critical being for instance the Anti-Microbial Resistance (AMR) areas. This paper is part of a larger research agenda on inefficiencies of medical markets and analytics of health care, with various business models (double-sided markets with platforms, induced supply and induced demand with new types of information search and patient involvement). The following table illustrates main areas for algorithmic developments on such markets [9] [Table 1].

Table 1: Illustrates main areas for algorithmic developments on such markets.

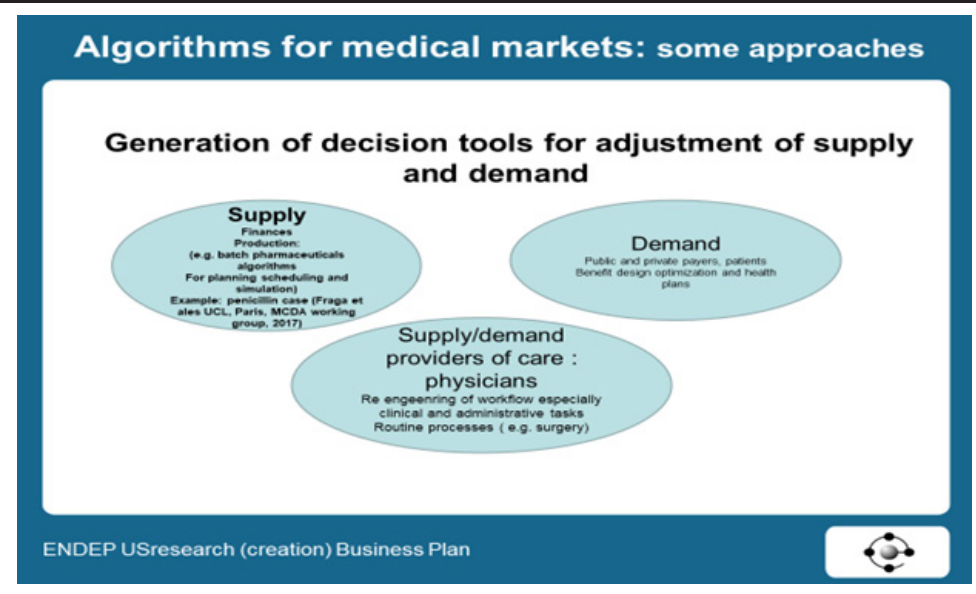

Analytics in health care is a major area for algorithms development both from the industry and the payer side, but also at the interaction of supply and demand, especially with physicians and other providers of care: On the supply side, business analytics methods have been very used for a long time, especially in finance (project management, research planning models [10] and production department for planning, scheduling, production process design (e.g. specific algorithms for optimization of batch processes in pharmaceutical manufacturing, case study of penicillin production) [11]. Other approaches are also used on health systems, based on engineering methods for quality improvements in healthcare organization. For instance, they contribute to re design workload and allocations of administrative and clinical tasks in medical practices (e.g. internal and external administrative transactions with health plans and other providers such as referrals and secondary care). In addition, transaction cost economic analysis can be useful to improve governance of healthcare organizations.

Transactions are mainly human transactions and exposed to bounded rationality (limited capacity to absorb new medical knowledge, opportunism and self- interest) and may limit efficiency to redesign workloads. Such an analysis also helps to identify uncertainty areas in medical practices such as pandemics, failures of computer system, loss of liability insurance [12]. Used in 
a political process, transaction cost approach may also be used to identify key decision points in complex political and bureaucratic administration of healthcare budgets [13]. On the demand side, public and private payers use algorithms, especially actuaries, for benefit designs and optimization of insurance plans. New methodologies and statistical models are also under development, in order to integrate more physician and patient preferences in the move towards precision medicine [14].

\section{References}

1. Basu A, Jena AB, Philipson TJ (2011) The impact of comparative effectiveness research on health and health care spending. J Health Econ 30(4): 695-706.

2. Jena $A B$, Philipson TJ (2008) Cost effectiveness analysis and innovation. J Health Econ 27(5): 1224-1236.

3. Gold MR, Patrick DL, Torrance GW (1996) Cost effectiveness in Health and Medicine. Oxford University Press.

4. Neumann PJ, Cohen JT, Weinstein MC (2014) Updating Cost Effectiveness- the curious resilience of the 50,000 per Qaly threshold. N Engl J Med 371(9): 796-797.

5. Jayadev A, Stiglitz J (2009) Two ideas to increase innovation and reduce pharmaceuticals costs and prices. Health Affairs 28(1): w165-w168.
6. Huttin C (2009) Is it possible to use Quality-adjusted Life years (Qaly) model in a value-based pharmaceutical policy (a response to Jayadev and Stiglitz) web exclusive Health Affairs. E-Letter.

7. Reich MR (2019) Political Economy for Health Bull World Health Organization. 97: 514 .

8. (2017-2018) Ispor Value Assessment framework report.

9. Huttin CC (2019) Development of an algorithmic price for health care services. Communication EURO-K 30 Analytics in Healthcare stream, Ireland p. WB-31.

10. Nichols NA (1994) Scientific Management at Merck: an interview with CFO Judy Lewent. Harvard Business.

11. Fraga ES, Salhi A, Talbi EG (2018) On the impact of representation and algorithm selection for optimization in process design: motivating a meta-heuristic framework; Operation Research/computer interfaces series. France 62: 141-149.

12. Huttin C, Berkeley (2005) Working paper, a case study on solo versus group practice using a transaction cost economic approach in primary care (project with the California Medical Association).

13. Huttin CC (2014) The 3Ps theory: new developments (EUPHA,2007). European Journal of Public Health, Belgium 17(Suppl2): 176.

14. Huttin CC, Hausman J (2019) Development of a choice model for physicians with random preferences application on type II diabetes. Value in Health. 